course, is to equalize the refraction of the two axes in which the astigmatism is most marked.

A modification has therefore been introduced which consists in a second " $\mathrm{V}$ " and the object of this is to enable the surgeon to call the patient's attention to two lines at right angles to each other, and to work on these two lines only.

By this means one can avoid much of the confusion that arises from the answers of patients with irregular astigmatism. The method of using the new test is to render the patient sufficiently myopic in the usual way so that only one or possibly two or three lines are left clear on the chart. If these lines are on the right side, the " $\mathrm{V}$ " with the red star is moved until it joins at the clearest line, if on the left side, the other " $V$ " is used. In the former case a red number on the indicator below the fan will notify the axis at which the correcting minus cylinder should be placed, while in the latter case a black number will do so. Cylinders are then inserted until the two lines at right angles to each other are of equal density, other lines on the chart being entirely ignored. By this means a considerable saving of time is effected, and the patient is able to say at once which line is the clearer, by naming the " $\mathrm{V}$ " which points to the line: that with or without the "star."

\title{
ANNOTATION
}

\section{Mediaeval Ophthalmic Treatment in use To day}

\author{
" Excellent herbs had our fathers of old- \\ Excellent herbs to ease their pain- \\ Alexanders and Marygold, \\ Eyebright, Orris, and Elecampane, \\ Basil, Rocket, Valerian, Rue, \\ (Almost singing themselves they run) \\ Vervain, Dittany, Call-me-to-you- \\ Cowslip, Melilot, Rose of the Sun, \\ Anything green that grew out of the mould \\ Was an excellent herb to our fathers of old."
}

For the past eighteen months a man, aged 80 years, has attended our out-patient department with a mature cataract on one side, and an acuity of $6 / 9$ on the other, after correction of half-a-dioptre of hypermetropia. The good eye has a single streak of opacity, downwards and inwards. Three months ago he said that his sight was worse, and an acuity of $6 ! 12$ was all that could be obtained. When seen, at the end of June, he was in a great state of excitement because his vision had improved, as he said, through using 
eyebright. He had certainly recovered his acuity of $6 / 9$; and as a matter of interest we asked him how he had used the herb. $\mathrm{He}$ said that he had taken a solution of it by the mouth and had also dropped the solution into the eye. He was proposing, if we agreed, to drop the solution into the cataractous eye, to see if it would " shift" the cataract. We told him that so far as we knew this could do no harm, and that it might interest him to know that, in using it, he had gone backwards about 300 years. "Nich. Culpepper, gent., Student in Astrology and Physic," in his "English Physician Enlarged," gives a page to eyebright. He says as follows :-

" Common eye-bright is a small low herb, rising up usually but with one blackish green stalk a span high, or not much more, spread from the bottom into sundry branches, whereon are set small and almost round, yet pointed dark green leaves, finely snipped about the edges, two always set together, and very thick. At the joints with the leaves, from the middle upwards, come forth small white flowers, steeped with purple and yellow spots, or stripes; after which follow small round heads, with very small seed therein. The root is long, small, and thready at the end. It groweth in meadows and grassy places in this land.

" It is under the sign of the Lion, and Sol claims dominion over it. If this herb were but as much used as it is neglected, it would half spoil the spectacle-makers trade; and a man would think, that reason should teach people to prefer the preservation of their natural before artificial spectacles; which that they may be instructed how to do, take the virtues of eye-bright as followeth :The juice, or distilled water of eye-bright, taken inwardly in white wine or broth, or dropped into the eyes for divers days together, helpeth all infirmities of the eyes that cause dimness of sight. Some make conserve of the flowers to the same effect. Being used any of the ways, it also helpeth a weak brain or memory. This tunned up with strong beer, that it may work together, and drunk; or the powder of the dried herb mixed with sugar, a little mace, and fennel seed, and drunk, or eaten in broth; or the said powder made into an electuary with sugar, and taken, hath the same powerful effect to help and restore the sight decayed through age; and Arnoldus de Villa Nova saith, it hath restored sight to them that have been blind a long time before."

Milton, it will be recalled, makes Michael remove the film from Adam's eye, " then purged with euphrasy and rue, the visual nerve, for he had much to see." Euphrasy is eyebright, and our old patient seems to be following classical precedents. 